\title{
A comparative study on medical comorbidities among children with autism spectrum disorder and controls in a children's hospital
}

\author{
*Miyuru Chandradasa ${ }^{1}$, Yasodha Rohanachandra ${ }^{2}$, Dulangi Dahanayake ${ }^{2}$, Darshani Hettiarachchi², \\ Malsha Gunathilake ${ }^{3}$, Roshan Fernando ${ }^{3}$, Swarna Wijetunge ${ }^{4}$
}

Sri Lanka Journal of Child Health, 2017; 46(3): 262-266

\begin{abstract}
Introduction: Autism spectrum disorder (ASD) is a neurodevelopmental disorder, in which medical disorders are known to occur higher than in the general paediatric population. This may indicate either that the neurodevelopmental disorder is acting as a risk factor or sharing a common pathophysiological mechanism with the medical disorder. We could not access any publications focusing on medical comorbidities in autism from Sri Lanka.
\end{abstract}

Objective: To compare the prevalence and types of medical comorbidities between children with ASD and outpatient controls presenting to a children's hospital in Sri Lanka.

Method: This was an observational analytical study using a case control design. Seventy three consecutive new enrolments diagnosed as ASD at the child psychiatric services of Lady Ridgeway Hospital were recruited to the study group. An age and gender matched group of children presenting to the outpatient department with minor physical problems were recruited as the comparison group. The presence of a medical disorder was determined retrospectively by perusal of medical records.

Results: The prevalence of febrile seizures, epilepsy, bronchial asthma, atopic dermatitis and recurrent gastrointestinal symptoms in the child were higher in the ASD group compared to the control group. The differences of the rates between groups for bronchial asthma and recurrent gastrointestinal symptoms were statistically significant. Also, pregnancy induced hypertension

${ }^{1}$ Lecturer in Psychiatry, Faculty of Medicine, University of Kelaniya, ${ }^{2}$ Senior Registrar in Child and Adolescent Psychiatry, ${ }^{3}$ Registrar in Psychiatry, ${ }^{4}$ Consultant Psychiatrist, Lady Ridgeway Hospital for Children, Colombo

*Correspondence: miyuruc@kln.ac.lk

(Received on 04 January 2017: Accepted after revision on 20 February 2017)

The authors declare that there are no conflicts of interest

Personal funding was used for the project.

Open Access Article published under the Creative

Commons Attribution CC-BY CC and gestational diabetes mellitus in the mother was higher in ASD group.

Conclusions: The probability of co-occurrence of certain medical disorders is significantly higher in children with ASD (neurological, respiratory, gastrointestinal and dermatological disorders) in comparison to controls.

DOI: http://dx.doi.org/10.4038/sljch.v46i3.8329

(Key words: Autism spectrum disorder, comorbidity, neurodevelopmental disorders, children)

\section{Introduction}

Autism spectrum disorder (ASD) is a neurodevelopmental disorder that begins in early life. According to the diagnostic criteria, children with ASD show deficits in social interaction / communication and restricted repetitive behaviours ${ }^{1}$. In a previous study from Sri Lanka, it was shown that poor development of speech is the primary concern of parents to seek help in children later diagnosed as autism. Symptoms related to social impairment were given less prominence by the carers. Furthermore, among the participants of this study $18.8 \%$ of children had comorbid medical disorders $^{2}$.

Previous studies have found increased prevalence of medical disorders such as epilepsy, inflammatory bowel disease, diabetes mellitus type I, sleep disorders and muscular dystrophy in children with ASD compared to the general paediatric population ${ }^{3,4}$. The presence of medical comorbidities is not considered in the diagnosis of ASD and clinicians might not emphasize enough on detecting and managing these associated medical disorders.

In relevance to aetiological associations, either the presence of a neurodevelopmental disorder may be a risk factor to develop a medical disorder or both disorders may have risen from a shared pathology such as a genetic variant ${ }^{5}$. There have been several studies indicating increased prevalence of medical disorders in neurodevelopmental disorders. However we could not find any published studies comparing children with ASD and controls on the presence of medical comorbidities from Sri Lanka. 


\section{Objective}

To compare the prevalence and types of medical comorbidities between children with ASD and that of controls, presenting to a children's hospital in Sri Lanka.

\section{Method}

Children obtaining services of the child and adolescent mental health services of the Lady Ridgeway Hospital for children (LRH) were considered for the study. This was an observational analytical study using a case control design. Seventy three consecutive new clinic enrolments diagnosed as ASD during a period of six months were included in the study group. Further 73 age and gender matched children presenting to the outpatient department of the hospital were included in the control group. The control group was selected using a combination of simple random sampling and systematic sampling. A set of random numbers from an online random number generator was used to select three days of each month of the entire study period of six months. On each day the first patient was selected from the outpatient department register randomly and thereafter every $10^{\text {th }}$ patient was considered for recruitment using systematic sampling. Up to five patients were recruited on each day until the target of 73 age and gender matched pairs were achieved. In the situation, where the child selected was diagnosed with a mental disorder or refused participation, the next register entry was considered. Any child diagnosed of having a congenital disorder was excluded from the study as these disorders are known to be associated with identified medical disorders.

The diagnoses were made via detailed clinical evaluations conducted by the consultant psychiatrist, according to the $5^{\text {th }}$ edition of the diagnostic and statistical manual of mental disorders (DSM-5) ${ }^{1}$. The clinical diagnosis was supported by the use of a structured assessment tool, which was the childhood autism rating scale version II (CARS-2) ${ }^{6}$. CARS-2 is a behaviour rating scale completed by the clinician, which helps in diagnosing autism in children above two years of age. The scale comprises of 15 items focusing on areas of ASD such as, relating to people, imitation and emotional response to others. When using the CARS-2, the clinician rates the child on a four point response scale and the ratings are based on the frequency, intensity and duration of the items concerned.

An interviewer administered semi-structured questionnaire was used to collect the socio- demographic details. The presence of a medical disorder in life was determined by a prior recorded diagnosis made by a consultant paediatrician after relevant clinical, biochemical and imaging investigations in the child and by a consultant physician in the mother after clinical and biochemical assessments during the antenatal period. In each participant, their past medical diagnosis cards, clinic records and other relevant documents were considered for data collection. Regarding the antenatal period of participants, any medical disorder that the mothers suffered during that period was considered for the study. In relevance to gastrointestinal symptoms, it was evident from the records that even though many children were assessed and treated for these symptoms, a conclusive diagnosis was not arrived at in the majority. Since ASD and gastrointestinal comorbidities are thought to be related, the authors decided to include recorded details of assessment of children who presented with constipation, chronic diarrhoea and gastroesophageal reflux for study purposes.

Written informed consent was obtained from a parent in all children. The ethics approval was obtained from the ethics review committee of LRH. The data was entered using the EPIDATA software version 3.0 and analysed using the SPSS software version 16. The statistical significance of the comparisons was done by calculating the odds ratios and related confidence intervals.

\section{Results}

The study group comprised 73 children with ASD, with a mean age of 5.4 years $(\mathrm{SD}=2.6)$, ranging from 2-13 years. The control group comprised 73 age and gender matched children, who presented to the outpatient department of the same hospital, with a mean age of 5.2 years ( $\mathrm{SD}=2.5$ ), ranging from 213 years. Boys comprised $86 \%$ of each group. Table 1 depicts the prevalence of medical comorbidities in each group and the statistical significance.

The prevalence of pregnancy induced hypertension, gestational diabetes mellitus in the mothers during the antenatal period, presence of a past diagnosis of febrile seizures, epilepsy and atopic dermatitis were higher in the ASD group compared to that of the controls, but the differences were not statistically significant. There were significantly higher rates of bronchial asthma and recurrent gastrointestinal symptoms among the participating children with ASD compared to that of controls. 
Table 1: Prevalences of medical comorbidities among participants and their mothers during the antenatal period, in children with autism spectrum disorder (ASD) and controls.

\begin{tabular}{|l|l|l|l|l|}
\hline \multicolumn{1}{|c|}{ Group } & $\begin{array}{c}\text { ASD } \\
(\mathrm{n}=73)\end{array}$ & $\begin{array}{c}\text { Controls } \\
(\mathrm{n}=73)\end{array}$ & $\begin{array}{c}\text { Odds ratio } \\
\text { (Confidence interval 95\%) }\end{array}$ & $\begin{array}{c}\text { Significance } \\
\text { at CI }=95 \%\end{array}$ \\
\hline $\begin{array}{l}\text { Pregnancy induced } \\
\text { hypertension in mother }\end{array}$ & $07(09.6 \%)$ & $05(06.8 \%)$ & $1.44(0.43$ to 4.77$)$ & $p=0.548$ \\
\hline Gestational diabetes in mother & $08(11.0 \%)$ & $06(08.2 \%)$ & $1.37(0.45$ to 4.17$)$ & $p=0.575$ \\
\hline Febrile seizures & $08(11.0 \%)$ & $03(04.1 \%)$ & $2.87(0.73$ to 11.29$)$ & $p=0.131$ \\
\hline Epilepsy & $02(02.7 \%)$ & $01(01.4 \%)$ & $2.02(0.17$ to 22.87) & $p=0.567$ \\
\hline Bronchial asthma & $18(24.6 \%)$ & $03(04.1 \%)$ & $7.63(2.13$ to 27.25) & $p=0.001$ \\
\hline Atopic dermatitis & $03(02.7 \%)$ & $00(00.0 \%)$ & $7.29(0.37$ to 143.85$)$ & $p=0.191$ \\
\hline $\begin{array}{l}\text { Recurrent gastrointestinal } \\
\text { symptoms }\end{array}$ & $29(39.7 \%)$ & $13(17.8 \%)$ & $3.04(1.42$ to 6.51$)$ & $p=0.004$ \\
\hline Any medical comorbidity & $40(54.7 \%)$ & $21(28.7 \%)$ & $3.00(1.51$ to 5.95) & $p=0.001$ \\
\hline
\end{tabular}

\section{Discussion}

The current study on medical disorders found that $54.7 \%$ of children with ASD had identified recurrent or persistent medical comorbidities when compared to only $28.7 \%$ in the control sample. The probability of a child with ASD having bronchial asthma was 7.6 times higher than for a child in the control group. Similarly, the probability of having atopic dermatitis was 7.3 times higher than for the control group. Co-occurrence of ASD with disorders with immunological aetiology is widely reported in the literature. A recent molecular genetic study revealed shared immune components between ASD and multiple co-morbid medical disorders ${ }^{7}$. It has also been proposed that autism is based on immune mediated mechanisms and implicates the possibility of an aetiological association between bronchial asthma and autism ${ }^{8}$. This Hygiene hypothesis also attempts to address the possible reasons for the rise in prevalence of this disorder worldwide ${ }^{8}$. Presence of dermatological conditions such as atopic dermatitis has been found to be related to $\mathrm{ASD}^{9}$. In our study three children with ASD had atopic dermatitis whilst there were none reported among the controls. However, the differences are not statistically significant. Any association between dermatological conditions and ASD could be due to common immunological pathways ${ }^{9}$. It is of interest to note that in a study conducted in the USA found a significantly higher prevalence of autoimmune disorders such as psoriasis in mothers during pregnancy in mothers with children having ASD, compared to controls ${ }^{10}$.

Symptoms of gastrointestinal disease, such as constipation, chronic diarrhoea and gastroesophageal reflux were present in $39.7 \%$ of children with ASD. However, due to the lack of valid clinical records, specific diagnoses were unavailable. The probability of gastrointestinal symptoms was three times higher in children with ASD. Studies have shown an association between gastrointestinal disorders such as gastroenteritis and inflammatory bowel disease and $\mathrm{ASD}^{3,4}$. More recent studies have focused on a role of gut microbiome in the aetiology of ASD and related gastrointestinal disorders ${ }^{11}$. On the contrary, however, large studies have not supported the long standing belief, based mainly on case reports, about the link between inflammatory bowel disease such as coeliac disease and $\mathrm{ASD}^{12}$.

The probability of having febrile seizures and/or epilepsy was more than twice in children with ASD in comparison to control sample, although this was not statistically significant. Many studies have reported significant increase in occurrence of seizures among children with ASD, compared to the general paediatric population ${ }^{13,14}$. In addition the onset of seizures has been implicated in autistic regression ${ }^{13}$. Febrile seizures are also more prevalent among children with $\mathrm{ASD}^{14}$. Due to the high prevalence of medical disorders in children with neurodevelopmental disorders, these are now debated to be whole body disorders involving peripheral organ systems, rather than being confined to the brain ${ }^{5}$.

Although there is no direct link between medical conditions in pregnancy and comorbidities in a child, an association has been found between gestational diabetes mellitus and pregnancy induced hypertension and risk of having a child with autism later ${ }^{15}$. In our study prevalence of gestational diabetes and pregnancy induced hypertension in the mothers were slightly higher among children with ASD than controls, but these differences were not statistically significant. Factors such as maternal medication use during pregnancy and advanced parental age have also been implicated in the same publication as risk factors for $\mathrm{ASD}^{15}$.

Use of a control group for comparison allowed the estimation of the probability of medical disorders in children with ASD. However, the small sample size and being hospital based limit the effectiveness of the outcome and generalizability of the results. Also, poverty of clinical information available 
especially on gastrointestinal comorbidities in children with ASD was a major limitation. It is vital that this aspect is further studied in depth due to its well-known risks in ASD.

\section{Clinical relevance}

This study draws attention to the co-occurrence of several medical conditions in children with ASD in Sri Lanka. Though extensively studied elsewhere in the world, this is the first such study here. The implication is that both the developmental and the medical aspects should be managed together to prevent adverse effects on each other. In neurodevelopmental disorders, certain behavioural disturbances are known to occur from concomitant medical problems ${ }^{16}$. The risk of missing one or the other of the problems is high depending on the treatment setting and the presenting complaints.

\section{Conclusion}

The probability of co-occurrence of certain medical disorders is significantly higher in children with ASD in comparison to a control group.

\section{References}

1. American Psychiatric Association. Diagnostic and Statistical Manual of Mental Disorders. $5^{\text {th }}$ ed. rev. Washington, DC: American Psychiatric Association; 2013.

2. Perera H, Jeewandara $\mathrm{K}$, Guruge $\mathrm{C}$, Seneviratne S. Presenting symptoms of autism in Sri Lanka: analysis of a clinical cohort. Sri Lanka Journal of Child Health 2013; 42(3): 139-43.

https://doi.org/10.4038/sljch.v42i3.6017

3. Kohane IS, McMurry A, Weber G, MacFadden D, Rappaport L, Kunkel L, et al. The co-morbidity burden of children and young adults with autism spectrum disorders. PLoS One 2012; 7(4):e33224. https://doi.org/10.1371/journal.pone.0033 224

PMid: 22511918 PMCid: PMC3325235

4. Doshi-Velez F, Ge Y, Kohane I. Comorbidity clusters in autism spectrum disorders: an electronic health record timeseries analysis. Pediatrics 2014; 133(1):e54-63.

https://doi.org/10.1542/peds.2013-0819

PMid: 24323995 PMCid: PMC3876178

5. Plummer JT, Gordon AJ, Levitt P. The genetic intersection of neurodevelopmental disorders and shared medical comorbidities-relations that translate from Bench to Bedside. Frontiers in Psychiatry 2016; 7:142.

https://doi.org/10.3389/fpsyt.2016.00142

PMid: 27597832 PMCid: PMC4992686

6. Schopler E, Reichler RJ, Renner BR. The childhood autism rating scale (CARS). Los Angeles: Western Psychological Services; 2002.

7. Nazeen S, Palmer NP, Berger B, Kohane IS. Integrative analysis of genetic data sets reveals a shared innate immune component in autism spectrum disorder and its co-morbidities. Genome Biol. 2016; 17(1):228. https://doi.org/10.1186/s13059-016-1084$\mathrm{z}$

PMid: 27842596 PMCid: PMC5108086

8. Becker KG. Autism, asthma, inflammation, and the hygiene hypothesis. Medical Hypotheses 2007; 69(4):731-40. https://doi.org/10.1016/j.mehy.2007.02.01 9

PMid: 17412520 PMCid: PMC2048743

9. Billeci L, Tonacci A, Tartarisco G, Ruta L, Pioggia G, Gangemi S. Association between atopic dermatitis and autism spectrum disorders: a systematic review. American Journal of Clinical Dermatology 2015; 16(5):371-88. https://doi.org/10.1007/s40257-015-01455

PMid: 26254000

10. Croen LA, Grether JK, Yoshida CK, Odouli R, Van de Water J. Maternal autoimmune diseases, asthma and allergies, and childhood autism spectrum disorders: a case-control study. Archives of Pediatrics and Adolescent Medicine 2005; 159(2):151-7.

https://doi.org/10.1001/archpedi.159.2.151 PMid: 15699309

11. Vuong HE, Hsiao EY. Emerging Roles for the Gut Microbiome in Autism Spectrum Disorder. Biol Psychiatry 2017; 81(5):411-23. https://doi.org/10.1016/j.biopsych.2016.08 .024

PMid: 27773355

12. Ludvigsson JF, Reichenberg A, Hultman CM, Murray JA. A nationwide study of the association between coeliac disease 
and the risk of autistic spectrum disorders. JAMA Psychiatry 2013; 70(11):1224-30. https://doi.org/10.1001/jamapsychiatry.20 13.2048

PMid: 24068245 PMCid: PMC3884520

13. Tuchman R, Rapin I. Epilepsy in autism. Lancet Neurology 2002; 1(6):352-8. https://doi.org/10.1016/S14744422(02)001 60-6

14. Rossi PG, Parmeggiani A, Bach V, Santucci M, Visconti P. EEG features and epilepsy in patients with autism. Brain and Development 1995; 17(3):169-74. https://doi.org/10.1016/03877604(95)0001 9-8
15. Gardener H, Spiegelman D, Buka SL. Prenatal risk factors for autism: comprehensive meta-analysis. The British Journal of Psychiatry 2009; 195(1):7-14. https://doi.org/10.1192/bjp.bp.108.051672 PMid: 19567888 PMCid: PMC3712619

16. Guinchat V, Cravero C, Diaz L, Périsse D, Xavier J, Amiet $\mathrm{C}$, et al. Acute behavioural crises in psychiatric inpatients with autism spectrum disorder (ASD): recognition of concomitant medical or non-ASD psychiatric conditions predicts enhanced improvement. Res Dev Disabil. 2015; 38: 242-55.

https://doi.org/10.1016/j.ridd.2014.12.020 PMid: 25575287 